\title{
Health impact assessment of exposure to inhalable particles in Lisbon Metropolitan Area
}

\author{
D. Dias, O. Tchepel \& C. Borrego \\ CESAM \& Department of Environment and Planning, \\ University of Aveiro, Portugal
}

\begin{abstract}
This study is focused on the assessment of potential health benefits in Lisbon Metropolitan Area, Portugal, using the limit values defined by the new European Directive (2008/50/CE) for short and long-term exposure to $\mathrm{PM}_{10}$. For this purpose, the methodology of the WHO for Health Impact Assessment and Apheis guidelines for data collection was applied. The time series of $\mathrm{PM}_{10}$ concentrations measured within the study area at urban background stations together with demographic data and health indicators were considered. An improved methodology using population mobility data that describes daily average Origin-Destination trips is proposed in this work to analyse the number of persons exposed. The results provide quantitative information on the number of attributable cases potentially prevented annually by reducing $\mathrm{PM}_{10}$ concentration to the levels established by the Air Quality Directive and proposed by WHO guidelines for this pollutant. An intercomparison of two approaches to process input data for the health risk analysis provides information on the sensitivity of the applied methodology.
\end{abstract}

Keywords: health impact assessment, urban air pollution, $P M_{10}$, exposure assessment, Lisbon Metropolitan Area.

\section{Introduction}

Scientific evidence on the effects of air pollution on human health has been increasing in recent years. Several issues remain open, but many epidemiological studies have demonstrated the importance of air pollution, including the 
atmospheric particulate matter (PM), as a risk factor for human mortality and morbidity [1-3].

The recently adopted European directive (2008/50/CE) revises the annual limit values for $\mathrm{PM}_{10}$ previously defined by the Framework Directive $(1999 / 30 / \mathrm{EC})$ and has established new quantitative standards for $\mathrm{PM}_{2.5}$. However, PM threshold levels to which exposure does not lead to adverse effects on human health have not been identified yet and given that there is a substantial inter-individual variability in exposure and in the response, it is unlikely that any standard or guideline value will lead to a complete protection for every individual against all possible adverse health effects of particulate matter [4].

This study provides a quantitative assessment of the potential benefits to human health associated with the reduction of short and long-term exposure to atmospheric particles with aerodynamic diameter less than or equal to $10 \mu \mathrm{m}$ $\left(\mathrm{PM}_{10}\right)$ in the Lisbon Metropolitan Area (Portuguese: Área Metropolitana de Lisboa, or AML).

For this purpose, the WHO methodology for quantitative assessment of the health impact of air pollution was applied to the study area. This methodology requires prior knowledge of different variables, such as exposure concentrations time series, number of people exposed, current mortality rates for each health indicator and the quantitative relationship between exposure and health effects. This information was processed in accordance with Apheis (Air Pollution and Health: a European Information System) guidelines for data collection [5]. Additionally, an alternative approach to process the population data taking into account daily average population mobility have been proposed in this study in order to improve estimations of the exposure.

\section{Methodology}

The Lisbon Metropolitan Area centred in the Portuguese capital city of Lisbon, was selected in this study for the heath impact assessment. AML is the largest population agglomeration in Portugal in which resided about 2782205 inhabitants in 2004 (about 26\% of the national population), divided into 19 municipalities and covering a total area of $2962.6 \mathrm{~km}^{2}$, which corresponds to about $3.3 \%$ of national territory. The Tagus River divides the AML municipalities on Lisbon District at North and Setubal District at South (Figure 1). Because of data availability, the study period is focused on 2004.

\subsection{Quantification of attributable cases}

The quantification of health risk applied in this study is conducted in terms of the number of cases attributable to air pollution and is based on relative risk (RR) estimates which is defined as "increased risk per given increase in pollution level" [6]. Thus, RR is a function of the difference in pollution level:

$$
\mathrm{RR}=\exp \left[\beta \times\left(X-X_{0}\right)\right]
$$

where:

$\beta$ - Risk coefficient derived from epidemiological studies 


$$
\begin{aligned}
& X-\text { Current pollutant concentration }\left[\mu \mathrm{g} \cdot \mathrm{m}^{-3}\right] \\
& X_{0} \text { - Target or threshold concentration of pollutant }\left[\mu \mathrm{g} \cdot \mathrm{m}^{-3}\right] .
\end{aligned}
$$

The health outcomes in a given population can be estimated based on Relative Risk (RR) and the frequency of the health outcome in the population (I) thus providing the number of cases attributed (NA) to air pollution exposure (eq. (2)):

$$
\mathrm{NA}=\mathrm{I} \times \frac{\sum([R R(c)-1] \times p(c))}{\sum[R R(c) \times p(c)]}
$$

where:

$$
\begin{aligned}
& p(c) \text { - Proportion of the target population in category c of exposure } \\
& \mathrm{I} \text { - Underlying frequency of the outcome in the population. }
\end{aligned}
$$

The programme PSAS-9 developed by the French Surveillance System on Air Pollution and Health [7] is used in this study as a support tool. This tool enables the achievement of an automated and standardized health risk assessment for several indicators of air pollution and health indicators calculating the number of premature deaths prevented annually due to a reduction of exposure to PM levels to the selected "target" concentration.

In this study, the PSAS-9 model was implemented to assess the number of premature deaths associated with short-term (1-2 days and 40 days), and also associated with long-term exposure to $\mathrm{PM}_{10}$. The target concentration is selected in accordance with the legislation limits (Directive 2008/50/CE) and served as a basis for the pollution reduction scenarios definition.

The results provide estimates of the number of prevented deaths attributable to air pollution in the target population, for different PM levels reduction scenarios and assuming that there is a causal relationship between atmospheric particle concentration and the observed health effects.

\subsection{Air quality data}

Exposure concentration is one of the key pieces of information required for the health impact assessment. To obtain this data, time series of $\mathrm{PM}_{10}$ concentrations measured at background air quality stations of the national network located within AML were processed and analysed. From 15 stations located within AML, only 7 are urban background stations and only 4 from these stations were selected, taking into account the data completeness $(>85 \%)$ for $\mathrm{PM}_{10}$ measurements (Figure 1).

For evaluation of short-term effects associated to the air pollution exposure, daily average concentrations calculated from the data observed during the year 2004 were used. The running annual average concentrations for 2 calendar years (2003 and 2004) were estimated for evaluation of long-term effects.

Two approaches to processing the air quality data are tested in the study. The first one does not account for the spatial variations of the pollution within the study area and considers the average values obtained from the four background stations while the second approach attributes the pollution measurements to each municipality as a function of the proximity to the monitoring point. 
The urban background stations are not homogeneously distributed within the metropolitan area and reveal different pollution levels. The Mem-Martins station presents a greater percentage of days with lower concentrations (less than 30 $\mu \mathrm{m} . \mathrm{m}^{-3}$ ), while the Olivais station located within the Lisbon urban area has registered the highest daily concentrations. The frequency distribution of the concentration values measured during the study period is asymmetrical relative to the mean value with positive skew (Figure 2).

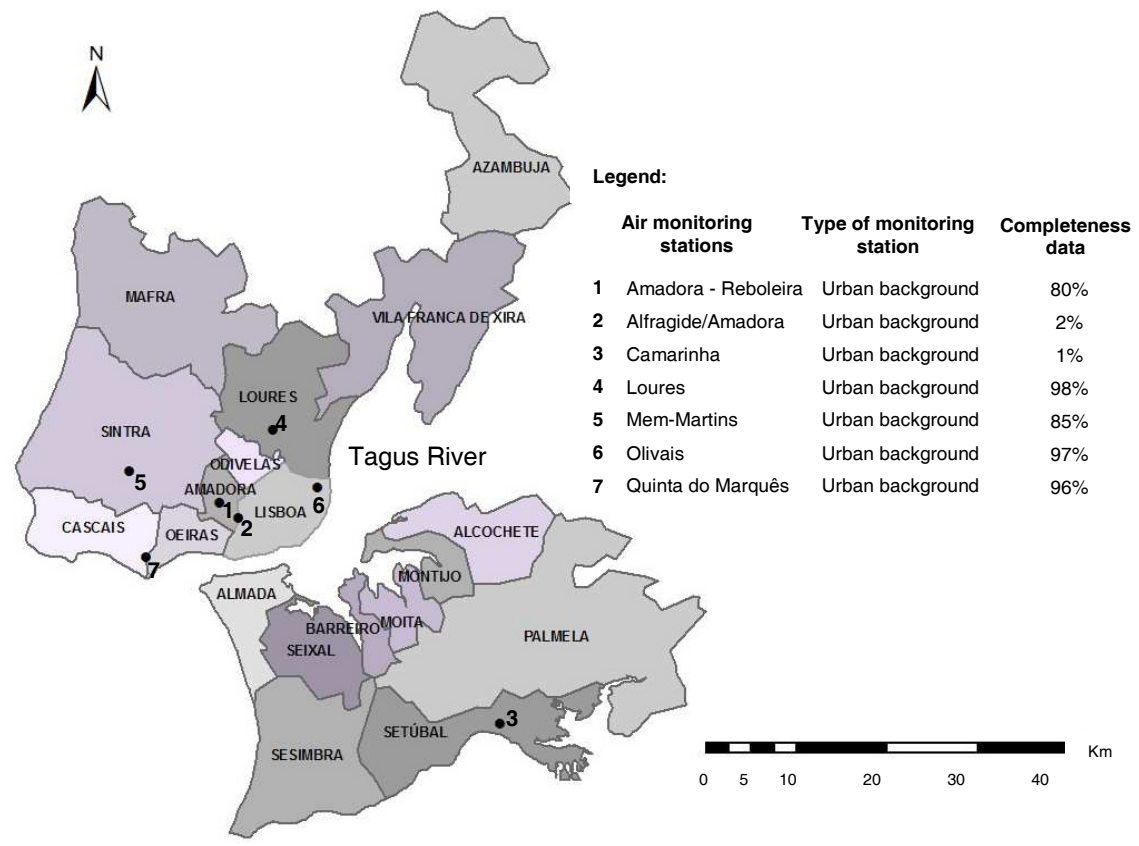

Figure 1: Area of study and geographic location of the particulate matter monitoring stations in AML, in the year 2004.

Comparison of the observation data with the daily limit value of $50 \mu \mathrm{m} . \mathrm{m}^{-3}$ not to be exceed more than 35 times during a calendar year (2008/50/CE), reveals that only the Mem-Martins station obeyed this regulation, registering 30 days of exceedences. However, it should be noted that the Mem-Martins station had a data collection rate of $85 \%$ only.

The annual average levels of $\mathrm{PM}_{10}$ obtained for the background stations are below the legislation limit $\left(40 \mu \mathrm{g} . \mathrm{m}^{-3}\right)$ and varying between 25.5 and $32.4 \mu \mathrm{g} . \mathrm{m}^{-3}$ for the AML study area (Figure 3).

\subsection{Population mobility}

The population mobility data may provide important information on spatial and temporal distribution of inhabitants required for the exposure quantification. The data obtained from the National Statistics Institute (INE) [8] concerning daily 


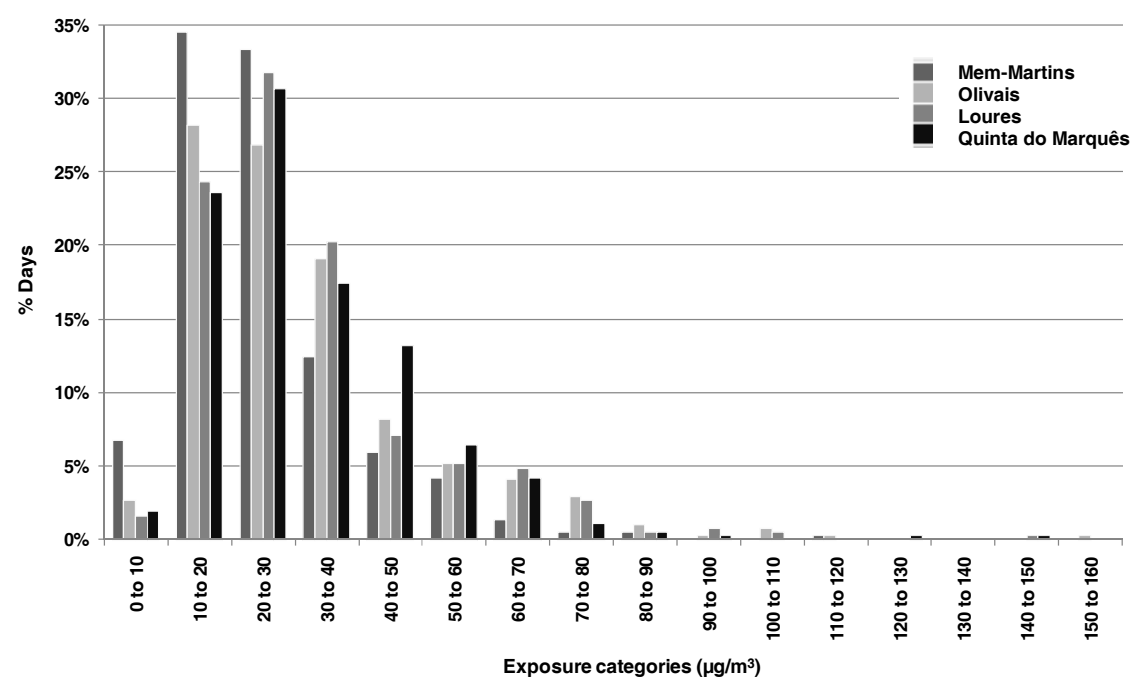

Figure 2: $\quad$ Frequency distribution of daily concentrations of $\mathrm{PM}_{10}$ measured in AML during 2004 at urban background stations.

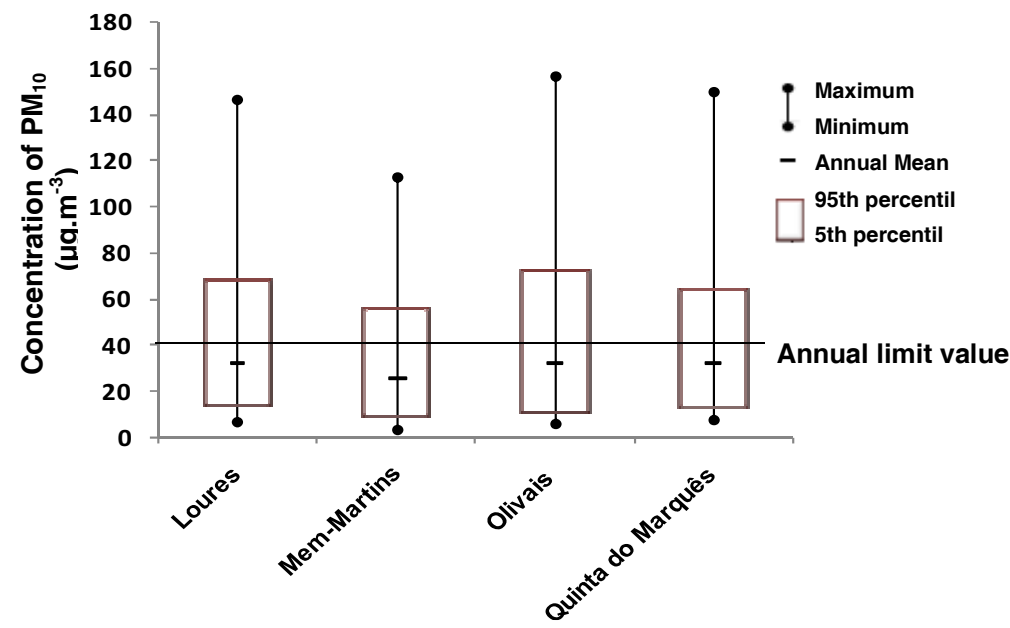

Figure 3: Statistical parameters for $\mathrm{PM}_{10}$ concentrations measured in AML during 2004 at urban background stations.

average Origin-Destination trips for AML was used in this study. One of the relevant characteristics of the study area is centralisation of working places in Lisbon city and an expansion of suburban dormitories around Lisbon. In all the residents of the AML, about $40 \%$ are travelling outside the residence place, showing Lisbon as the main destination. Only 5\% of the population are working or studying outside of AML. 
For each municipality, the mobility data together with the number of residents was used to characterise temporal and spatial variations of the exposed population. The income and outcome flows consider daily trips of the inhabitants to places of work or study thus providing a population distribution pattern during the daytime working hours. The statistical data on resident population is allocated for nighttime hours. Therefore, the average population exposed to inhalable particles is calculated for each municipality taking into account the time of exposure and information on the population flows (Table 1).

Table 1: $\quad$ Population data expressed as [number of inhabitants] considered in the health impact assessment.

\begin{tabular}{cccccc}
\hline Municipality & $\begin{array}{c}\text { Resident } \\
\text { population } \\
\text { (R) }\end{array}$ & $\begin{array}{c}\text { Income } \\
(\mathbf{I})\end{array}$ & $\begin{array}{c}\text { Outcome } \\
(\mathbf{O})\end{array}$ & $\begin{array}{c}\text { Daytime } \\
\text { population } \\
(\mathbf{D = R + I - O )}\end{array}$ & $\begin{array}{c}\text { Average } \\
\text { population } \\
(\mathbf{1} / \mathbf{2}[\mathbf{R}+\mathbf{D}] \mathbf{)}\end{array}$ \\
\hline Alcochete & 14966 & 1438 & 3401 & 13003 & 13985 \\
Almada & 165363 & 23296 & 87903 & 100756 & 133060 \\
Amadora & 176239 & 23401 & 56429 & 143211 & 159725 \\
Azambuja & 21508 & 1273 & 8136 & 14644 & 18076 \\
Barreiro & 78992 & 8513 & 35621 & 51884 & 65438 \\
Cascais & 181444 & 18113 & 90136 & 109421 & 145432 \\
Lisbon & 529485 & 359604 & 235356 & 653733 & 591609 \\
Loures & 199231 & 24605 & 99868 & 123968 & 161599 \\
Mafra & 62009 & 2834 & 28899 & 35944 & 48977 \\
Moita & 70226 & 3024 & 31858 & 41392 & 55809 \\
Montijo & 40466 & 5028 & 18200 & 27294 & 33880 \\
Odivelas & 143995 & 7817 & 74195 & 77617 & 110806 \\
Oeiras & 168475 & 37273 & 84370 & 121378 & 144927 \\
Palmela & 58222 & 11569 & 27225 & 42566 & 50394 \\
Seixal & 164715 & 8712 & 82132 & 91296 & 128005 \\
Sesimbra & 44046 & 2309 & 19881 & 26474 & 35260 \\
Setúbal & 120117 & 14564 & 55007 & 79674 & 99896 \\
Sintra & 409482 & 24043 & 200983 & 232543 & 321012 \\
Vila Franca de Xira & 133224 & 7449 & 65775 & 74898 & 104061 \\
\hline & & & & &
\end{tabular}

\subsection{Health indicators and concentration-response functions (CR)}

The risk of developing a disease due to exposure to agents with different levels of intensity and duration can be assessed using a statistical model for an exposure-effect relationship [9]. Once identified and selected health indicators to analyse, the concentration-response functions may be obtained from epidemiological studies.

The health indicators considered in this study include mortality rates (deaths/100000 inhabitants) expressed as all-cause mortality (excluding external causes) (ICD 10: A00-Y99) available at district level (Table 2). 
Table 2: $\quad$ Annual mortality rate per 100000 inhabitants and mortality for allcause mortality (excluding external causes) (ICD 10: A00-Y99).

\begin{tabular}{ccccc}
\hline \multicolumn{2}{c}{$\begin{array}{c}\text { Mortality rate } \\
\text { (deaths/100 000 inhabitants) }\end{array}$} & \multicolumn{3}{c}{ Annual mortality } \\
\hline District of Lisbon & District of Setubal & $\begin{array}{c}\text { District of } \\
\text { Lisbon }\end{array}$ & $\begin{array}{c}\text { District of } \\
\text { Setubal }\end{array}$ & AML \\
\hline 888.20 & 891.90 & 17986.87 & 6752.70 & 24736.56 \\
\hline
\end{tabular}

Table 3: Relative Risk (RR) for all-cause mortality (excluding external causes) (ICD 10: A00-Y99) associated with exposure to $\mathrm{PM}_{10}$.

\begin{tabular}{|c|c|c|c|}
\hline & \multicolumn{2}{|c|}{$\begin{array}{c}\text { Risk Assessment to Short-Term } \\
\text { Exposure }\end{array}$} & \multirow{2}{*}{$\begin{array}{c}\text { Risk Assessment to Long- } \\
\text { Term Exposure }\end{array}$} \\
\hline & $\begin{array}{l}\text { Very short-term } \\
\text { (1 - } 2 \text { days })\end{array}$ & $\begin{array}{c}\text { Cumulative } \\
\text { short-term } \\
\text { (40 days) } \\
\end{array}$ & \\
\hline $\begin{array}{c}\text { Relative risk } \\
\text { For } 10 \mu \mathrm{g}^{-3} \text { increase }^{-} \\
(95 \% \text { Confidence limits })\end{array}$ & $\begin{array}{c}1.006 \\
(1.004-1.008)\end{array}$ & $\begin{array}{c}1.01227 \\
(1.0081-1.0164)\end{array}$ & $\begin{array}{c}1.043 \\
(1.026-1.061)\end{array}$ \\
\hline
\end{tabular}

Due to the absence of the information on exposure-effect relationship derived specifically for the study area, the values recommended by European study Apheis-3 [6] were adapted as presented in Table 3. To provide a better understanding of the short-term effects of atmospheric particles on human health over time, two types of concentration-response functions are considered: (i) effects associated with exposure to very short term, usually 1 or 2 days, and (ii) the health effects due to cumulative exposure of up to 40 days $[10,11]$.

\subsection{Health impact assessment scenarios}

The health impact assessment implemented in this study is based on the calculation of the number of deaths associated with exposure to inhalable particles. Several pollution reduction scenarios have been defined taking into account the legislation limit values and guidelines values considered as a "target" concentration.

The following assessment scenario to estimate the acute effects of short-term exposure to $\mathrm{PM}_{10}$ on total mortality (excluding external causes) over a 1-year period was used:

- $50 \mu \mathrm{g} \cdot \mathrm{m}^{-3}$ - Daily limit value [Directive 2008/50/CE] and guideline value proposed in the latest review of "Air Quality Guidelines" from WHO [4].

The risk assessment associated with chronic effects due to long-term exposure to $\mathrm{PM}_{10}$ considers the following scenarios:

- $40 \mu \mathrm{g} . \mathrm{m}^{-3}$ - Annual limit value [Directive 2008/50/CE].

- $20 \mu \mathrm{g} . \mathrm{m}^{-3}$ - Guideline value proposed at the last review of "Air Quality Guidelines" from WHO [4]. 
These scenarios are used to evaluate the potential benefits to human health due to reduction of the current pollution levels to the defined target values.

\section{Results and discussion}

The results obtained for short and long-term exposure, expressed as a number of attributable cases, are presented and discussed in this topic. Furthermore, two alternative approaches to process the population data and air quality measurements (with and without spatial variability) are compared.

The number of deaths annually avoided due to the reduction of short and long-term exposure is presented in Table 4. The values due to the short-term exposure are estimated for 1-2 and 40 days exposure considering all internal causes mortality (ICD 10: A00-R99) and reduction of the current $\mathrm{PM}_{10}$ levels in terms of daily average concentration to $50 \mu \mathrm{g} . \mathrm{m}^{-3}$.

The potential benefits for human health associated with the reduction of long term exposure were evaluated taking into account the guidelines proposed by WHO $\left(\mathrm{PM}_{10}\right.$ annual average concentration $\left.20 \mu \mathrm{g} \cdot \mathrm{m}^{-3}\right)$ because the pollution levels of $\mathrm{PM}_{10}$ measured during the study period are already below the legislation limit $\left(40 \mu \mathrm{g} . \mathrm{m}^{-3}\right)$ defined by the Directive.

Table 4: $\quad$ Potential benefits due to the reduction of short-term and long-term exposure in AML considering all internal causes mortality (ICD 10: A00-R99). Values presented in parenthesis correspond to the $95 \%$ confidence interval.

\begin{tabular}{|c|c|c|c|c|}
\hline \multirow{2}{*}{$\begin{array}{l}\text { Air Pollutant } \\
\text { Indicator }\end{array}$} & \multicolumn{2}{|c|}{$\begin{array}{l}\text { Potential reduction in the } \\
\text { number of deaths } \\
\text { (no spatial variations in the input data) }\end{array}$} & \multicolumn{2}{|c|}{$\begin{array}{c}\text { Potential reduction in the } \\
\text { number of deaths considering } \\
\text { population mobility and spatial } \\
\text { variations of } \mathrm{PM}_{10} \text { concentrations }\end{array}$} \\
\hline & $\begin{array}{c}\text { Number of } \\
\text { deaths } / 100000 \\
\text { inhabitants }\end{array}$ & Number of deaths & $\begin{array}{c}\text { Number of } \\
\text { deaths } / 100 \\
000 \\
\text { inhabitants } \\
\end{array}$ & Number of deaths \\
\hline \multicolumn{5}{|c|}{ Risk Assessment to Short-Term Exposure } \\
\hline $\begin{array}{c}\mathbf{P M}_{10}^{1} \\
\text { very short- } \\
\text { term } \\
\text { (1-2 days) }\end{array}$ & $\begin{array}{c}1.06 \\
(0.71-1.42)\end{array}$ & $\begin{array}{c}29.49 \\
(19.70-39.70)\end{array}$ & $\begin{array}{c}1.86 \\
(1.24-2.49)\end{array}$ & $\begin{array}{c}51.76 \\
(34.42-69.18)\end{array}$ \\
\hline $\begin{array}{c}\text { PM }_{10}^{1} \\
\text { cumulative } \\
\text { short-term } \\
\text { (40 days) }\end{array}$ & $\begin{array}{c}2.22 \\
(1.46-2.99)\end{array}$ & $\begin{array}{c}61.84 \\
(40.59-83.12)\end{array}$ & $\begin{array}{c}3.88 \\
(2.55-5.21)\end{array}$ & $\begin{array}{c}107.87 \\
(70.84-144.95)\end{array}$ \\
\hline \multicolumn{5}{|c|}{ Risk Assessment to Long-Term Exposure } \\
\hline $\begin{array}{c}\mathbf{P M}_{10}{ }^{2} \\
\text { Long-term }\end{array}$ & $\begin{array}{c}39.24 \\
(23.71-55.69)\end{array}$ & $\begin{array}{c}1091.61 \\
(659.64-1549.54)\end{array}$ & $\begin{array}{c}41.25 \\
(24.91-58.61)\end{array}$ & $\begin{array}{c}1147.68 \\
(692.93-1630.61)\end{array}$ \\
\hline
\end{tabular}

\footnotetext{
1 Reduction to $50 \mu \mathrm{g} . \mathrm{m}^{-3}$
}

${ }^{2}$ Reduction to $20 \mu \mathrm{g} \cdot \mathrm{m}^{-3}$. 
Additionally to the conventional approach to process the population data using census information on the number of residents for each municipality, the population mobility data were considered in the current study as described in topic 2.3. The risk assessment results obtained from this alternative approach are presented in Table 4. As could be seen from the table, the results obtained from these two approaches are significantly different. The first approach does not consider spatial variation in the input data, while the second approach considers the population mobility and spatial variations of $\mathrm{PM}_{10}$ concentrations within the Lisbon Metropolitan Area.

The potential benefit estimated by the second approach with the population mobility data is about $43 \%$ higher than estimations provided by the traditional approach for short-term and about $4.9 \%$ for long-term exposure. This fact is related with population daily trips to the Lisbon city area characterised by higher pollution levels then dormitory suburbs and, therefore, resulting in higher current exposure level estimated by the methodology.

As it was mentioned before, the effects of air pollution on human health depend not only on the pollutant concentration, but also on time of exposure of the individuals. In this context, spatial variation of the $\mathrm{PM}_{10}$ concentration and mobility of the individuals are of extreme importance. Moreover, the distinct results obtained with and without population mobility are important to analyse a sensitivity of the risk assessment methodology to the input data.

Since the methodology applied in this study for the risk assessment is based on the Apheis guidelines, a comparison of the results have been performed. Thus, for short-term exposure considering the reduction of daily average concentration of $\mathrm{PM}_{10}$ to $50 \mu \mathrm{g} \cdot \mathrm{m}^{-3}$, the benefit estimated by APHEA-3 study consists of avoiding around 2 and 3 deaths per 100000 inhabitants due to all internal causes as an average for European cities. The results obtained in the current study for AML are slightly lower (1.06 and 2.22) then the average European values. However, consideration of the population mobility that is of higher importance for the study area will result in higher benefits of 1.86 and 3.88 avoided deaths per 100000 inhabitants for the very short term (1-2 days) and short-term cumulative (40 days), respectively.

\section{Conclusion}

In the present study, the human health risk assessment associated with short-term and long-term exposure to $\mathrm{PM}_{10}$ in the Lisbon Metropolitan Area (AML) is performed. Various assessment scenarios considering pollution reduction strategies were analysed providing quantitative information on the benefits in terms of the number of deaths annually avoided.

The results obtained for AML are slightly lower than the average European values reported by APHEA-3 project and represent 1.06 and 2.22 annually avoided deaths per 100000 inhabitants due to all internal causes for the very short term (1-2 days) and short-term cumulative (40 days), respectively.

Due to the higher population mobility observed within the study area which could significantly affects the exposure quantification, an improved methodology 
to process population statistics taking into account daily average population income/outcome is proposed in this work. Therefore, this methodology improves the representation of spatial and temporal variability in the population distribution pattern and, consequently, the population exposure quantification. The health benefits obtained for AML considering population mobility in the input data are about $43 \%$ higher than those provided by the traditional approach and correspond to potential reduction of 52-108 deaths considering short-term assessment. Moreover, this study shows that implementation of WHO guideline values for the long-term $\mathrm{PM}_{10}$ exposure could reduce current mortality in the study area about $4.6 \%$.

Finally, an intercomparison of two approaches applied in this study demonstrates an influence of the input data on the exposure indicators and, therefore a sensitivity of the risk assessment methodology.

\section{References}

[1] Brunekreef B, Dockery DW, Krzyzanowski M. Epidemiologic studies on short-term effects of low levels of major ambient air pollution components. Environ Health Perspect. 1995.

[2] Pope CA, Burnett RT, Thun MJ, Calle EE, Krewski D, Ito K, Thurston G. Lung Cancer, Cardiopulmonary Mortality, and Long-term Exposure to Fine Particulate Air Pollution. Journal of Air and Management Association. 2002.

[3] Krzyzanowski M, Wojtyniak B. Ten-year mortality in a sample of an adult population in relation to air pollution. J Epidemiol Community Health. 1982.

[4] WHO. Air Quality Guidelines for particulate matter, ozone, nitrogen dioxide and sulfur dioxide - Global update 2005 Summary of risk assessment. Geneva. 2006.

[5] Medina S, Plasencia A, Artacoz L, Quenel P, Katsouyanni K, Mucke HG, De Saeger E, Krzyzanowsky M, Schwartz J, and the contributing members of the Apheis group. Apheis Monitoring the Effects of Air Pollution on Public Health in Europe. Scientific report, 1999-2000. Saint-Maurice: Institut de Veille Sanitaire, 2001.

[6] APHEIS. Health Impact Assessment of Air Pollution and Communication Strategy. 3rd Year Report (2002-2003). July. 2004.

[7] Le Tertre A, Quenel P, Eilstein D, et al. Short-term effects of air pollution on mortality in nine French cities: a quantitative summary. Arch Environ Health. 2002.

[8] Instituto Nacional de Estatística (INE). Movimentos Pendulares e Organização do Território Metropolitano: Área Metropolitana de Lisboa e Área Metropolitana do Porto 1991-2001. Instituto Nacional de Estatística. Lisboa. 2003.

[9] Corvalan C.F, Smith K.R, Kjellstrom T. How much global ill health is attributable to environmental factors? Epidemiology Resources. 1999. 
[10] Zanobetti A, Schwartz J, Samoli E. The temporal pattern of mortality responses to air pollution: a multicity assessment of mortality displacement. Epidemiology. V13, No 1. 2002.

[11] Zanobetti A, Schwartz J, et al. The temporal pattern of respiratory and heart disease mortality in response to air pollution. Environmental Health Perspectives. V11, No 9. 2003. 